\title{
Preocupaciones crecientes en la práctica de la cirugía: de la anarquía al dilema
}

\author{
Growing worries in the practice of surgery: from anarchy to dilemma
}

$\mathrm{D}$ esde el inicio de la misión que me ha sido confiada en esta nueva etapa de la revista Cirujano General, puedo afirmar que la respuesta a mi convocatoria ha sido sorprendentemente positiva. Dicha respuesta contrapone el prejuicio de que el cirujano es sólo un artesano sin capacidad de reflexión. El cirujano reflexivo carecía de un espacio adecuado dónde publicar sus inquietudes; el espacio afortunadamente se ha dado y la necesidad de reflexión ha encontrado un cauce.

En el presente número se destacan tres preocupaciones crecientes de las que se habla entre distintos grupos de cirujanos: la Academia Nacional de Cirugía, la Asociación Mexicana de Cirugía General (AMCG), la Universidad Nacional Autónoma de México (UNAM), la Universidad Anáhuac y la Facultad de Medicina del Instituto Tecnológico y de Estudios Superiores de Monterrey (ITESM) mismos que se reunieron en el XIII Encuentro Nacional del Cirujano bajo los auspicios de la AMCG, esfuerzo multiinstitucional para llamar la atención y despertar la conciencia en torno a este problema cuyas consecuencias futuras están ya a la vuelta de la esquina.

La primera es que no hay control regulatorio ni de calidad respecto de los requisitos mínimos para ejercer la especialidad de cirugía general, pues como escribe el Dr. Jorge Cervantes en su colaboración en este número, el título "Médico Cirujano" habilita de facto legalmente para ejercer la especialidad sin tener que pasar por el entrenamiento de un programa de residencia ni por el Consejo Mexicano de Cirugía General para obtener la certificación. En otras palabras, un médico recién egresado puede emprender, legalmente, cualquier tipo de operación sin ningún control, siendo los únicos límites su imaginación y su temeridad. Lo que es peor, como muchas cosas en este país, ni los números son confiables ni hay un custodio, el Estado, que vigile a los custodios, a la academia, las asociaciones, los colegios, el Consejo y a la Dirección General de Profesiones. Dicho de otra forma, en la anarquía predomina el caos.

La segunda, como quedó patente en el encuentro antes mencionado, es que pese a las evaluaciones del Programa Único de Especialidades Médicas (PUEM), no se ha podido establecer un estándar mínimo de calidad con el que los residentes egresen siendo cirujanos generales, ni un estándar de vigilancia durante la residencia, igualmente mínimo, de los jóvenes cirujanos generales de los cuales $40 \%$, de acuerdo con otro artículo del Dr. Cervantes, fracasará en el intento de obtener la certificación por parte del Consejo. ${ }^{1}$

La tercera preocupación, reflejada en la colaboración del Dr. Alberto Campos, es que ante el dilema de denunciar la iatrogenia es posible que 
la coerción del sistema sea más eficiente que la obligación moral de cada uno de nosotros, con amparo en un juramento mediante el cual supuestamente somos una confraternidad. Por otra parte, al parecer es una percepción general que la iatrogenia aumenta de manera rampante, aunque de ello se hable poco y se documente menos. Habrá que preguntar hasta qué grado la confraternidad es capaz de autorregularse y de lograr una mínima consistencia ética ante los embates cada vez más frecuentes de actores externos.

Esconder la cabeza mientras se degrada el ecosistema quirúrgico de este país no soluciona nada, es un acto mediocre e inútil. Los cirujanos, como cuerpo colegiado, tendríamos si no una obligación moral, al menos el deber de mostrar una actitud congruente con lo que denunciamos en los foros, una actitud proactiva, altruista, crítica, colegiada, amigable hacia el entorno médico quirúrgico en el que el paciente es la razón de la medicina.

Celebro la respuesta que hemos tenido hasta el momento, a través de estas colaboraciones, a la propuesta de una reflexión sobre los propósitos de la cirugía en esta nueva etapa de la revista Cirujano General y al mismo tiempo reitero la invitación a los cirujanos a participar con contribuciones comprometidas, objetivas y bien fundamentadas sobre los problemas concretos que enfrenta la cirugía general contemporánea, más allá de la mera cirugía experimental y más allá del simple reporte de caso.

La revista Cirujano General es de todos, el foro y el placer editorial también lo son.

REFERENCIA

1. Cervantes J. Surgical education in Mexico. World J Surg. 2010; 34: 875-876.

\section{Dra. Abilene C. Escamilla Ortiz}

